\title{
La Publicidad Institucional de la Junta de Andalucía
}

\author{
$\mathrm{M}^{\mathrm{a}}$ Dolores FERNÁNDEZ POYATOS ${ }^{1}$ \\ Emilio FELIU GARCÍA ${ }^{2}$
}

Universidad de Alicante

\begin{abstract}
RESUMEN:
A partir de las inserciones publicitarias realizadas por la Junta de Andalucía durante el período 1999-2009, se analiza la evolución de la publicidad gubernamental andaluza perteneciente a los distintos ámbitos (Social, Político, Corporativo y Comercial) y sectores de la publicidad institucional, centrando nuestra atención, primordialmente, en tres cuestiones fundamentales: de qué, cuándo y dónde hace publicidad la Junta de Andalucía. El objeto de la investigación cuyos resultados se presentan en esta investigación es conocer el comportamiento de la Junta de Andalucía como anunciante.
\end{abstract}

PALABRAS CLAVE: publicidad institucional; gobierno; elecciones; medios; soportes.

TITLE: The Institutional Advertising of the Andalusian Government

\begin{abstract}
:
Since the advertising insertions done by the Andalusian Committee during the period of 1999-2009, it is analyzed the evolution of the Andalusian governmental advertising in several fields (Social, Political, Corporate and Commercial). This evolution is also studied in sectors of the institutional advertising, focusing the attention in three main issues: when, where and about what does the Committee make advertising of. The objective of this research, which results are presented in this work, is to clarify the behavior of the Andalusian Committee as advertiser.
\end{abstract}

KEY WORDS: institutional advertising; government; political elections; media.

\section{Introducción}

Siguiendo a Alameda y Fernández ${ }^{3}$, «lo institucional» puede considerarse de cuatro maneras distintas, según se haga con la institución: a) desde el interés público, b) como creadora de imagen de marca, c) desde la comunicación corporativa, o d) desde la significatividad social. En el primer caso se concibe la institución como un organismo que busca el interés general de los ciudadanos. Y partiendo de esta perspectiva, «sólo se concibe como publicidad institucional aquella realizada por las administraciones públi-

1 Profesora Contratada Doctora del Departamento de Comunicación y Psicología Social de la Universidad de Alicante. Miembro del Grupo de Estudios sobre Publicidad Institucional, Política y Social (GEPIPS). E-mail: dolores.fernandez@ua.es

2 Profesor Titular de Universidad de Comunicación Audiovisual y Publicidad. Departamento de Comunicación y Psicología Social de la Universidad de Alicante. Director del Grupo de Estudios sobre Publicidad Institucional, Política y Social (GEPIPS). E-mail: emilio.feliu@ua.es

3 Alameda GarCíA, D.; FernáNDEZ BlanCO, E. (2002): «Aproximación conceptual a la publicidad institucional», Sphera Publica: Revista de Ciencias Sociales y de la Comunicación, 2, 159-174. 
cas frente a la comunicación publicitaria de las empresas» ${ }^{4}$. El elemento diferenciador esencial es el carácter público/privado del sujeto emisor. Así, el rasgo caracterizador de la publicidad institucional es el carácter público del anunciante. La entenderemos, pues, como «el material comunicativo en formatos publicitarios emitido por el Estado en los distintos niveles de la Administración pública» ${ }^{5}$.

Esta publicidad «que se hace desde las instituciones y Administraciones Públicas» ${ }^{6}$, viene siendo objeto de una cierta atención por parte de los invetigadores en comunicación en la última década ${ }^{7}$. Desde la publicación de la monografía de García López ${ }^{8}$ se han venido produciendo una serie de investigaciones sobre diferentes aspectos (y desde distintas perspectivas) de esta forma de comunicación. Si bien algunos investigadores contraponen a la creciente importancia de esta forma de publicidad un escaso interés en ella como objeto de estudio ${ }^{9}$, lo cierto es que existen en España diversos investigadores y grupos de investigación que vienen prestando su atención de forma continuada a la publicidad institucional ${ }^{10}$.

En algunos casos, aun reconociendo que las administraciones utilizan la publicidad para distintos fines, se centra la atención en la publicidad social, que, sin embargo, no representa en absoluto -como veremos- el ámbito en el que se realiza el mayor esfuerzo publicitario.

\section{La regulación de la publicidad institucional en la Comunidad autónoma de Andalucía}

En la década de los noventa se gestan en España las primeras iniciativas parlamentarias para regular la publicidad institucional en forma de proposiciones de ley: en 1992

\footnotetext{
4 Ibídem, 160

5 PINEDA, A.; REY, J. (2009): «Propaganda y publicidad institucional», Questiones Publicitarias, 3, 12.

6 CORTÉs GONZÁlEZ, A. (2008): «Conceptualización de la publicidad institucional en su dimensión socializadora y educativa», Espacios Públicos, vol. 11, nº 22, 226-237.

7 AEAP (1991): La publicidad en la administración española, Madrid, AEAP. ALCARAZ, M. (1992): «Reflexiones sobre la publicidad institucional», en VV.VV.: El espacio televisivo a partir de la Directiva 89/552 de las Comunidades Europeas, Valencia, Ente RTVV. ARANES, J. I. (1996): «La comunicación institucional de la administración pública: entre la lógica autista-instrumental y la democrática», Zer, 1, 201-213. ORIOL, P. (2001): «Comunicación pública en el ámbito local», en VV.AA.: Dirección de comunicación empresarial e institucional, Barcelona, Gestión 2000, 249-274.

8 GARCÍA LÓPEZ, M. (2001): Publicidad institucional. El Estado anunciante, Málaga, Universidad de Málaga.

CORTÉs GONZÁLEZ, A. (2011): «La publicidad institucional en España. Una década en perspectiva», Razón y Palabra, 75.

10 Entre los grupos de investigación cabe citar a MAECEI (Método, Análisis y Estrategias de la Comunicación Empresarial e Institucional) en la Universidad de Sevilla, UNICA (Unitat d'Investigació en Comunicació Audiovisual) en la Universitat Pompeu Fabra, y GEPIPS (Grupo de Etudios sobre Publicidad Institucional, Política y Social) en la Universidad de Alicante. Otros investigadores han dedicado parte de sus trabajos a distintos aspectos de la publicidad institucional, como García López y Cortés González (Universidad de Málaga), Alvarado y De Andrés (Universidad de Valladolid) o Moragas i Espà (Universitat Autònoma de Barcelona).
} 
y 1993, en el Congreso de los diputados y en las Asambleas de Navarra y el País Vasco. Apenas unos años después, se promulgan las primeras leyes en Andalucía -1995-y en Extremadura -1996-, que resultaron ser efecto de dichas proposiciones; circunstancia que explica las coincidencias entre unas y otras ${ }^{11}$.

En lo que respecta a la comunidad andaluza, tres son las leyes que hasta la fecha se han promulgado: la Ley 5/1995, de 6 de noviembre, Reguladora de la Publicidad Institucional, derogada por la Ley 4/1999, de 11 de mayo, Reguladora de la Actividad Publicitaria de las Administraciones Públicas de Andalucía, que, a su vez, quedó derogada en la vigente Ley 6/2005, de 8 de abril, de igual título.

En la Exposición de motivos, la primera de estas leyes declara tener como fin principal el de «evitar toda competencia desleal promovida desde el sector público que incida negativamente en el pluralismo informativo», definiendo en su artículo 1 el ámbito subjetivo -sector público andaluz, en general-y el ámbito objetivo - publicidad- de su aplicación; los otros cinco artículos establecen normas que impiden que se utilice la publicidad como elemento de discriminación desde el sector público.

La Ley 4/1999, de 11 de mayo, Reguladora de la Actividad Publicitaria de las Administraciones Públicas de Andalucía nació por «Las dificultades que ha planteado la aplicación de la Ley 5/1995» (Exposición de motivos). En el artículo 2, se observa una diferencia clara en la delimitación del concepto de publicidad institucional; mientras en la del año 1995 se hace en sentido positivo, en la de 1999, se delimita tanto en sentido positivo, como negativo:

Las actividades publicitarias que desarrollen la Junta de Andalucía y las Administraciones locales andaluzas, así como los organismos, entidades de derecho público y sociedades mercantiles vinculadas o dependientes de aquéllas, participadas mayoritariamente de forma directa o indirecta, que no sean de carácter industrial o comercial. Queda excluida del ámbito de aplicación de esta Ley la publicidad normativa y otros anuncios de actos de la Administración que deban publicarse legalmente.

Otra diferencia se aprecia en el ámbito objetivo de aplicación. La Ley 5/1995 lo incluía en el artículo 1 con una clasificación en cuatro grupos; la de 1999, en el artículo 3 , establece sólo dos grupos; el primero, más amplio y de redacción más detallada y precisa, recoge prácticamente casi todos los grupos de la ley de 1995; entre los nuevos, destacan el de la difusión de la imagen de Andalucía y los fines de promoción turística; también es más minuciosa en la descripción de otras categorías, como por ejemplo, la de favorecer la existencia de hábitos saludable. El segundo grupo hace referencia únicamente a «Aquellas actividades, distintas de las anteriores, cuyo objeto es informar, con carácter general, sobre los proyectos, las realizaciones o logros en la gestión públi-

11 Véase Feliu Albaladejo, A. (2011): «La publicidad institucional en la arena parlamentaria española», Revista Latina de Comunicación Social, 66, La Laguna (Tenerife), Universidad de La Laguna, 454481. 
ca» (artículo 3, apartado b). Se trata de una categoría nueva, que se corresponde con la denominada «Información de actuaciones» de Infoadex.

La Ley 4/1999 también difiere en lo relativo a la contratación, pues agrupa en un solo artículo (5. Criterios de contratación) todo, frente a la ley de 1995, que lo repartía en tres. Asimismo, es relevante lo que atañe a la publicidad en períodos electorales, siendo más prolija la Ley 4/1999, que añade una Disposición Adicional para extender las limitaciones y garantías del Artículo 6 a todas las Administraciones Públicas y entes públicos, organismos, entidades de derecho público y sociedades mercantiles vinculadas o dependientes de aquéllas, que estén participadas mayoritariamente de forma directa o indirecta y que no sean de carácter industrial o comercial, cuando desarrollen actividades publicitarias en el ámbito de la Comunidad Autónoma de Andalucía ${ }^{12}$.

La Ley 6/2005, de 8 de abril, Reguladora de la Actividad Publicitaria de las Administraciones Públicas de Andalucía presenta una serie de cambios e innovaciones respecto a las normas precedentes, que son recogidas en la Exposición de motivos: primero, y como artículo 3, establece el ámbito objetivo definiendo lo que se entiende como actividad publicitaria de las Administraciones Públicas andaluzas; segundo, se amplían las limitaciones y garantías en períodos electorales; tercero, se adoptan medidas de transparencia para la actividad publicitaria; cuarto, se obliga a remitir al Parlamento de Andalucía la relación de contratos, subvenciones, etc. y quinto, se prohíben durante las campañas electorales actos que supongan la manifestación pública de inauguraciones y eventos similares ${ }^{13}$.

El artículo 3 se desarrolla en esta última ley en nueve puntos; de ellos, sólo los dos primeros son nuevos:

a) Promover valores y conductas que consoliden la democracia, la libertad, la convivencia y la solidaridad y

b) Implicar a la ciudadanía andaluza en el objetivo de lograr una sociedad cohesionada y avanzada en cuanto a conciencia cívica y progreso económico y social; el resto se encontraban, bien en la Ley 5/1995, bien en la Ley 4/1999.

Aquellos grupos que ya contemplaba la primera ley eran:

c) Informar a los ciudadanos de sus derechos y obligaciones,

h) Informar sobre la existencia, composición y funcionamiento de las instituciones públicas.

En la Ley 4/1999, eran de nueva incorporación:

d) Promover el ejercicio de derechos o el cumplimiento de deberes en condiciones de igualdad, carácter educativo, cultural, social, sanitario, de fomento de empleo u otros de análoga naturaleza,

f) Favorecer la existencia de hábitos saludables, individual o colectivamente,

12 Esta Disposición contiene dos cuestiones a considerar. Por una parte, supone la existencia de sociedades mercantiles "que no sean de carácter industrial o comercial", lo que parece una contradicción in terminis; por otra, sólo regula la actividad desarrollada por los sujetos públicos afectados en el ámbito de la propia Comunidad Autónoma, y no en el resto de los territorios del Estado.

13 Adelantándose así, en este punto, a lo contemplado en la reciente reforma de la LOREG. 
g) Difundir la imagen de Andalucía o del ámbito de cada Administración con fines de promoción turística,

i) Informar, con carácter general, sobre los proyectos y resultados en la gestión pública $^{14}$.

Sobre limitaciones y garantías en períodos electorales (artículo 6), es relevante, por novedoso, el apartado 3, que prohíbeeslóganes, simbología o elementos publicitarios identificables de los partidos políticos. Asimismo, los partidos políticos tampoco pueden utilizar durante la campaña electoral eslóganes, simbología o elementos publicitarios identificables con las campañas institucionales ${ }^{15}$.

Otra novedad en esta ley atañe a la obligación de hacer público «en el Boletín Oficial de la Junta de Andalucía y poner a disposición en internet la relación de las adjudicaciones de los contratos, ayudas, subvenciones y convenios en esta materia en los términos que la Ley precisa» (artículo 7); así como la de remitir al Parlamento de Andalucía, «con carácter cuatrimestral, la relación de los contratos, ayudas, subvenciones y convenios referidos en el párrafo anterior» (artículo 9).

Por último, insistir en la ya mencionada prohibición durante las campañas electorales de cualquier acto que suponga «la manifestación pública de presentaciones, inauguraciones y otros eventos similares, en general de proyectos, realizaciones o resultados de las Administraciones, organismos, entidades y sociedades a los que se refiere el artículo 2 de la presente Ley» (Disposición adicional primera).

En síntesis, la diferencia entre las tres leyes afecta a una redacción más minuciosa y precisa en sus diferentes artículos y a un ámbito objetivo más amplio, sobre todo, en lo concerniente a la publicidad institucional de los partidos políticos en períodos electorales, a la regulación de elementos publicitarios, símbolos, etc., que pueden identificarse con campañas institucionales, también en materia de control o consideración en lo relativo a difusión de medios. A lo largo de diez años, la legislación en este asunto por parte de la Comunidad autónoma andaluza demuestra una notable preocupación por las actuaciones transparentes, así como por solventar los vacíos e imprecisiones que, en la práctica y desarrollo, las distintas leyes han puesto de manifiesto.

14 Hay que subrayar, en este último apartado, la significativa supresión del sustantivo logros que sí aparecía en la Ley 4/1999.

15 Este artículo, que supone una verdadera novedad y que tuvo continuidad en casi todas las leyes posteriores, obliga a plantearse dos cuestiones. En primer lugar, la de qué se entiende por "elementos publicitarios"; si la locución es uno de ello (y entendemos que así debe considerarse), no podría utilizarse la misma voz en campañas institucionales de la Junta de Andalucía y en las político-partidistas del PSOE, como se haría durante la campaña electoral de 1996. Por otra parte, ¿puede una ley "Reguladora de la Actividad Publicitaria de las Administraciones Públicas de Andalucía" prohibir la utilización de elemento formal alguno a los partidos políticos?; dado el ámbito subjetivo de la ley (las administraciones públicas andaluzas), no parece ser de aplicación a otros posibles anunciantes, quedando, pues, las restricciones a las actuaciones de los partidos políticos fuera del objeto y del ámbito de aplicación de esta ley. 


\section{Metodología}

El presente trabajo se inscribe en el marco de una investigación más amplia, cuyo objeto de estudio es la publicidad institucional de los gobiernos autónomos realizada durante el periodo 1999-2009.

Entendemos por publicidad institucional «la actividad publicitaria promovida por las administraciones e instituciones públicas, así como por las empresas u organismos que de ellas dependen» ${ }^{16}$, partiendo de las consideraciones hechas en la introducción de este trabajo, así como de las distintas definiciones contempladas en las diferentes leyes que la regulan.

Se trata de un estudio exploratorio, pero necesario, y del que, según los resultados obtenidos, se desprenderán determinadas cuestiones a las que habremos de atender a la hora de plantear cualquier investigación acerca de la publicidad institucional.

El objetivo general de esta investigación es conocer el comportamiento de las administraciones públicas en tanto que anunciantes. Para ello se determinaron tres objetivos específicos, en relación con la publicidad realizada por la Junta de Andalucía en cuanto tal, dejando al margen, por tanto, la que pudieran realizar otras administraciones o instituciones públicas andaluzas. Dichos objetivos son:

- establecer de qué hace publicidad, esto es, determinar a qué sectores y ámbitos se adscriben las inserciones producidas;

- analizar cuándo hace publicidad, es decir, comprobar la distribución temporal de las diferentes campañas, considerando especialmente la posible influencia que pudiera tener la celebración de elecciones autonómicas;

- analizar qué medios y soportes son los más utilizados.

Son estos tres aspectos de tal importacia que, aparte otras consideraciones, constituyen el núcleo de todas las normas legales reguladoras de la publicidad institucional en España.

Para la consecución de estos objetivos, nos hemos servido de técnicas de análisis cuantitativo aplicadas a la base de datos de Infoadex, «herramienta de referencia obligada dentro del sector publicitario español» ${ }^{17}$, que contiene información a partir de 1999. Para nuestro estudio, hemos considerado todas las inserciones realizadas durante el período 1999-2009, pertenecientes al sector Servicios públicos y privados, categoría "Campañas de interés público» (según la nomenclatura utilizada en la base de datos Infoadex, tabla 1$)^{18}$. Los veintitrés productos incluidos en esta categoría son los que en nuestro trabajo hemos denominado «sectores», lo que significa separarnos, en esa cuestión, de la nomenclatura de Infoadex.

16 Feliu Albaladejo, A. (2008): «Los ámbitos de la publicidad institucional», en Feliu García, E. (ed.), Comunicación. Memoria, Historia y Modelos, Madrid, Edipo, 428.

17 MalalanA, A. (2004): «Fuentes de información para el análisis de la publicidad. Las bases de datos publicitarias e internet», Cuadernos de Documentación Multimedia, 15, 12.

18 No analizamos, por tanto, una muestra, sino el universo, la totalidad de los ítems. 
Tabla 1. Campañas de interés público

\begin{tabular}{|l|l|}
\hline Agua y energía & Impuestos \\
\hline Anti-Alcohol & Incendios \\
\hline Anti-Tabaco & Información de Actuaciones \\
\hline Anti-Droga & Limpieza y ecología \\
\hline Censos & Promoción de calidad \\
\hline Consumo & Sanidad \\
\hline Denominación de origen & Servicios militares y civiles \\
\hline Deportes & Tráfico \\
\hline Educación/Cultura/Investigación & Uso de transporte público \\
\hline Elecciones & Línea campañas interés público \\
\hline Empleo & Otros campañas interés público \\
\hline Imagen de Instituciones & \\
\hline
\end{tabular}

Fuente: Infoadex

De los datos que proporciona Infoadex -inserción, ocupación, inversión-, se ha utilizado el de inserción ${ }^{19}$ (número de apariciones de los anuncios en cada medio y soporte), por dos razones fundamentales: la ocupación (la mancha publicitaria o el tiempo ocupado por la publicidad) no resulta pertinente dados los objetivos de nuestro análisis; la inversión indica la cifra en euros, según la tarifa de los distintos soportes, no teniendo en cuenta ni los rappels o bonificaciones que éstos aplican a los anunciantes en función del volumen de contratación, ni los capítulos relativos a creatividad, realización y producción. Como señalan Álvarez y Reyes, estas cifras de inversión no son las reales, es decir, no se corresponden exactamente con las cantidades invertidas por los anunciantes en sus acciones publicitarias. El cálculo que realiza InfoAdex es indirecto, ya que mide a través de un amplísimo muestreo las inserciones de anuncios realizadas y luego infiere la inversión necesaria. Este sistema suele sobreponderar la inversión publicitaria real de las grandes compañías que, por su capacidad de negociación, obtienen grandes descuentos de los medios sobre las tarifas oficiales ${ }^{20}$.

Si las inversiones se calculan extrapolando el número de inserciones, éste resulta ser el dato primario. De ahí, lo oportuno de su utilización.

Si comparamos los datos de inversión con los del número de inserciones de los cinco principales sectores (Tabla 2), comprobamos que la desviación producida es, en la mayoría de los casos, poco apreciable. Así, por ejemplo las inserciones de «Información de actuaciones», que representan el 35,64\% del total, suponen el 35,24\% de la

19 Para el cálculo de la inserción, Infoadex asigna en el caso de marcas compartidas el 50\% a cada marca, por lo que con bastante frecuencia aparecen cifras con decimales.

${ }_{20}$ Álvarez, A.; Reyes, M I. (2011): «De la publicidad espectáculo a los valores emocionales: el sector de la energía en España» [en línea]. Area Abierta, 28 Dirección http://revistas.ucm.es/inf/ 15788393/articulos/ARAB1111130001A.PDF. Web visitada el 15/03/2011. 
inversión realizada durante todo el periodo considerado. Sólo se observa una desviación considerable en el caso de «Promoción de calidad», en el que el porcentaje de las inversiones supera en más de seis puntos al de las inserciones. Ello se debe, sin duda, a las diferencias en la utilización de medios y soportes (y, por tanto, de tarifas aplicadas) en este sector.

De cualquier manera, debemos insistir en que por el origen de los datos (observación directa en el caso de las inserciones, inferencia a partir de éstos de la inversión necesaria) son los de inserción los más fiables.

Tabla 2. Inserciones e inversión en los principales sectores. 1999-2009.

\begin{tabular}{|l|r|r|r|r|}
\hline Sector & Inserciones & \multicolumn{1}{c}{$\%$} & \multicolumn{1}{c|}{ Inversión } & \multicolumn{1}{c|}{$\%$} \\
\hline Inf. de actuaciones & 31846,5 & 35,64 & 71394195 & 35,24 \\
\hline Promoción de la calidad & 13188,0 & 14,76 & 43432455 & 21,43 \\
\hline Educación/Cultura/Investigación & 11398,5 & 12,75 & 24568292 & 12,12 \\
\hline Consumo & 6638,5 & 7,43 & 14950493 & 7,38 \\
\hline Imagen de instituciones & 5528,5 & 6,18 & 8187198 & 4,04 \\
Subtotal & $\mathbf{6 8 6 0 0 , 0}$ & 76,76 & $\mathbf{1 6 2 5 3 2 6 3 3}$ & 80,21 \\
\hline TOTAL & $\mathbf{8 9 3 4 0 , 5}$ & & $\mathbf{2 0 2 6 0 3 5 0 1}$ & \\
\hline
\end{tabular}

Elaboración propia a partir de Infoadex.

El período considerado (1999-2009) permite comprobar suficientemente la evolución diacrónica del esfuerzo publicitario realizado por la Junta de Andalucía. Comprende, además, determinados hitos, que pueden incidir y afectar la evolución de la publicidad institucional, como son la celebración de tres procesos electorales autonómicos -2000, 2004 y 2008-, y la existencia de tres leyes reguladoras de la publicidad institucional $(1995,1999$ y 2005).

\section{Resultados}

\subsection{La publicidad institucional de la Junta de Andalucía. Datos Generales}

Si atendemos al número de inserciones publicitarias producidas en todos los sectores de Infoadex, la Junta de Andalucía es el cuarto gobierno autonómico con 89.340,5, lo que significa un $7,8 \%$ del total de inserciones; por delante de ella, y de mayor a menor, se encuentran la Comunidad de Madrid con 232.065,5 inserciones (18,31\%), la 
Generalitat de Cataluña con $133.388,5(10,52 \%)$ y la Generalitat Valenciana con 102.416 inserciones $(8,08 \%)^{21}$.

En lo que respecta a sujetos públicos anunciantes, en la comunidad andaluza se produjeron, en el período analizado, un total de 146.367, por cuenta de 353 anunciantes, siendo el más importante de ellos la Junta de Andalucía con 89.340,5 (el 61,03\%). El ranking de los diez primeros anunciantes institucionales andaluces se muestra en la tabla 3, donde destaca, al margen de la Junta de Andalucía, el alto número de inserciones tanto del Ayuntamiento de Málaga -6.788-, como de la Diputación también de Málaga -6.053,5-, máxime al compararlo con otros organismos similares, alguno como el de Sevilla de gran relevancia.

Tabla 3. Inserciones por anunciantes públicos andaluces. 1999-2009

\begin{tabular}{|c|c|c|}
\hline Anunciante & Inserciones & $\%$ \\
\hline Junta de Andalucía & $\mathbf{8 9 . 3 4 0 , 5}$ & \multirow[t]{10}{*}{61,03} \\
\hline Ayto. Málaga & $6.788,0$ & \\
\hline Dip. Provincial Málaga & $6.053,5$ & \\
\hline Ayto. Córdoba & $3.444,5$ & \\
\hline Ayto. de Cádiz & $3.191,0$ & \\
\hline Ayto. Sevilla & $2.455,5$ & \\
\hline Dip. Provincial Sevilla & $2.454,0$ & \\
\hline Ayto. Granada & $1.783,0$ & \\
\hline Ayto. Almería & $1.718,5$ & \\
\hline Dip. Provincial Cádiz & $1.659,5$ & \\
\hline Total & & \multirow{4}{*}{81,22} \\
\hline 10 primeros anunciantes & 118.888 & \\
\hline Total & & \\
\hline Inserciones institucionales & $146.367,0$ & \\
\hline
\end{tabular}

Elaboración propia a partir de Infoadex.

21 Estos datos no se corresponden con la afirmación de que existe «una importante -aunque desequilibrada- actividad publicitaria de las comunidades analizadas, debido a la intensa labor publicitaria de las comunidades de Madrid y Valencia» (RodríGuez CENTENO, J.C.; GARRIDO, M.; RAMOS, M. (2008): «Análisis comparativo de la publicidad institucional de las comunidades autónomas: objetivos y cualidades discursivas», I+C Investigar la Comunicación, 9). Las comunidades que destacan sobremanera en relación con el resto son la madrileña y la catalana. La diferencia en los resultados se debe a los distintos periodos analizados, la distinta naturaleza de los ítems considerados y la metodología aplicada. El estudio de Rodríguez, Garrido y Ramos se refiere a la diversidad (número de espots diferentes), mientras que en nuestro análisis se mide la intensidad (número total de inserciones) de la actividad publicitaria. 
Como puede comprobarse, la actividad de los diez primeros anunciantes supone más de un ochenta por ciento del total de las inserciones de las administraciones andaluzas correspondientes a campañas de interés público, representando la de la Junta de Andalucía el 61,03 por ciento de las mismas.

\subsection{Las campañas de interés público de la Junta de Andalucía}

Como hemos visto, la Junta es el anunciante público más importante de la comunidad andaluza, y su actividad se centra de manera principal en el área de las campañas de interés público.

Centrándonos en éstas, hemos procedido al análisis de las tres variables siguientes: el sector al que pertenecen las inserciones (tabla 1), el período de tiempo en que se producen, y el medio/soporte en que aparecen.

\subsubsection{Sectores}

Los tres sectores con mayor representatividad - «Información de Actuaciones», «Promoción de la calidad»y «Educación/Cultura/Investigación»-suponen el 63,15\% del total. Podemos, por tanto, observar una clara concentración sectorial de la publicidad institucional del gobierno andaluz, que ha ido aumentando en los últimos años, llegando a alcanzar el 80,9\%, en 2009.

Entre todos los sectores, destacan, con un $35,64 \%$, las inserciones pertenecientes a «Información de actuaciones» $(31.846,5)^{22}$; si a éstas añadimos las de «Imagen de instituciones» $-5.528,5(6,18 \%)$-, se obtiene un $41,82 \%$ del total (Gráfico 1).

A mayor abundamiento, y en el extremo opuesto, llama la atención la falta de inserciones en el sector «Tráfico» ${ }^{23}$, así como la insignificancia del de «Uso de transporte público» $(0,1 \%)$, y la parca cantidad de las referidas a la prevención del consumo de alcohol, tabaco y drogas -4.100 entre las tres-, esto es, un 2,56 por ciento.

22 Lo mismo ocurre en los casos de la Xunta de Galicia (32,64\%), la Generalitat Valenciana $(34,76 \%)$ o la Generalitat Catalana (47,73\%), en los que es éste, con mucho, el sector predominante, como se refleja en Feliu García, E.; Quintas Froufe, N. (2010): «La Xunta de Galicia como anunciante», XII Foro de Investigación en Comunicación. La Comunicación institucional. Estado actual [Madrid, 25 de noviembre de 2010], (en prensa), en Feliu Albaladejo, A. y Feliu García, E. (2010): «Publicidad institucional en la Comunidad Valenciana. La Generalitat Valenciana como anunciante», XII Foro de Investigación en Comunicación. La Comunicación institucional. Estado actual [Madrid, 25 de noviembre de 2010], (en prensa) y en Feliu García, E.; Feliu Albaladejo, A. (2011): «La publicitat institucional a Catalunya», Comunicació: Revista de Recerca i d'Anàlisi, vol. 28 (2), Barcelona, Societat Catalana de Comunicació, 47-67.

Véase en lo sucesivo estas tres referencias en relación con los datos comparativos entre los distintos gobiernos autonómicos.

23 No sucede así en Cataluña, donde este sector es el tercero en orden de importancia. 
Gráfico 1. Inserciones por sectores.1999-2009

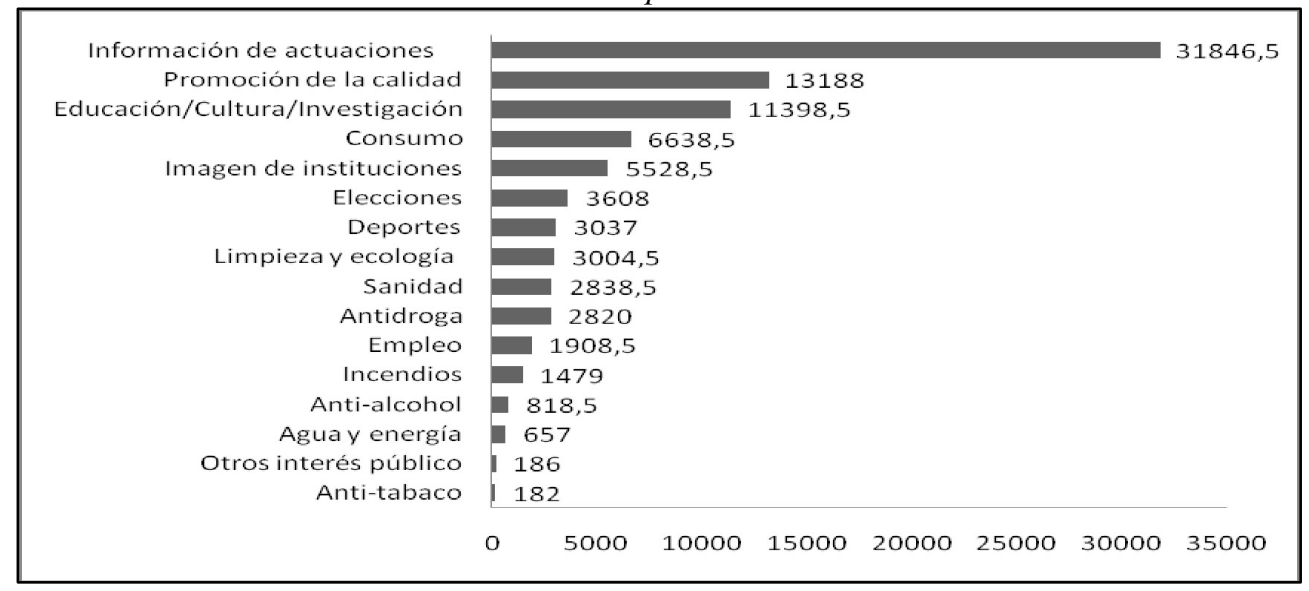

Elaboración propia a partir de Infoadex.

Alvarado y De Andrés ${ }^{24}$ señalan que las instituciones públicas utilizan la publicidad para tres fines básicos: comerciales, sociales o de imagen; entre las sociales destacan las campañas referidas a la salud y el bienestar público y social, la marginación y/o la discriminación, la protección del entorno natural y urbano, y la solidaridad internacional. Por su parte, Moragas ${ }^{25}$ las agrupa, de acuerdo con su temática, en seis categorías: sociales, políticas, culturales, socioeconómicas, de seguridad y medioambientales. Pero añade que no todas las campañas institucionales responden a intereses sociales tan evidentes, refiriéndose a las destinadas a informar de las acciones de los gobiernos o a promover la autoestima de los ciudadanos; campañas éstas que pueden ser más discutibles y también «más propagandísticas que informativo/persuasivas» ${ }^{26}$.

Pues bien, de lo observado en nuestro análisis se desprende que las campañas institucionales de la Junta de Andalucía se inscribirían fundamentalmente en el tipo de las propagandísticas (Moragas) o de imagen (Alvarado y De Andrés), lo que permite afirmar el carácter eminentemente corporativo (Feliu Albaladejo) de la publicidad institucional de la Junta de Andalucía ${ }^{27}$.

24 AlvarAdo, C.; DE ANDRÉS, S. (2005): «Una reflexión crítica sobre la publicidad estatal. El Estado ¿anunciante social?», Telos: Cuadernos de comunicación, tecnología y sociedad, 64, 67-73.

25 Moragas I SPÀ, M. de (2005): «Publicidad institucional: comunicación y civismo», Barcelona Metròpolis Mediterránia, 6, 72-77.

26 Sin entrar aquí en considerar las posibles diferencias entre propaganda y publicidad, admitamos que se trata de campañas publicitarias, por mucho que puedan tener naturaleza «propagandística». Y, en cualquier caso, son a todas luces mensajes informativo/persuasivos.

27 Este predominio de las inserciones pertenecientes al ámbito corporativo se da, igualmente, en la Comunidad Valenciana y en Cataluña; no así en el de Galicia, donde se observa una proporcionalidad equilibrada entre los tres fines señalados por Alvarado y De Andrés (comerciales, sociales y de imagen). 


\subsubsection{La temporalidad de las campañas de interés público}

La evolución cronológica (Gráfico 2), en términos cuantitativos, de la actividad publicitaria de la Junta de Andalucía presenta un perfil de dientes de sierra con tres años 2000,2003 y $2007-$, en los que se produce un incremento notable de las inserciones respecto a los años inmediatamente anteriores, de manera que no es muy descabellado proponer dos períodos: el primero abarcaría del año 1999 al 2002, con un moderado (bajo) nivel de inserciones: entre 4.971,5 y 6.977; el segundo, el resto, esto es, desde el año 2003 hasta el 2009, cuando se registran 9.974 inserciones (2003) y 8.511 (2009), pero con una inflexión ascendente considerable en el año 2007 (14.270,5 inserciones), precedida de dos momentos descendentes: años 2004 y 2005 y años 2008 y 2009.

Gráfico 2. Inserciones anuales. 1999-2009

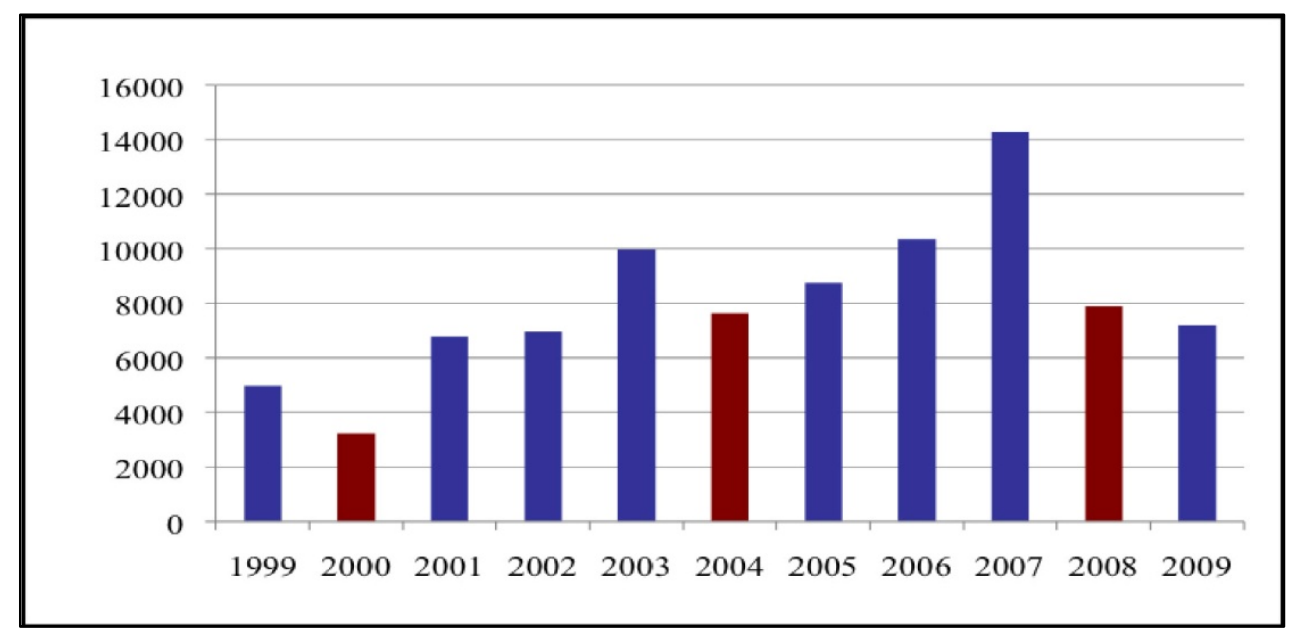

Elaboración propia a partir de Infoadex.

Los años de mayor actividad coinciden con los precedentes a los años de elecciones, lo que vendría a contradecir, en parte, lo señalado por Guerrero respecto al período de emisión de la publicidad institucional en el ámbito autonómico ${ }^{28}$. En su análisis contempla los datos agregados de las comunidades autónomas de Andalucía, Cataluña, Madrid, Valencia y País Vasco, correspondientes al período comprendido entre el 1 de abril de 2005 y el 31 de marzo de 2006, concluyendo que el 71,4\% de las inserciones

28 GUERRERO SERÓN, C.A. (2009): «La publicidad institucional durante el primer gobierno Zapatero (2005-2006): elementos formales y estrategias de comunicación», Questiones Publicitarias, Monográfico $\mathrm{n}^{\circ} 3,80 \mathrm{y}$ ss. 
se produjeron a mediados de legislatura, mientras que sólo el 2,0\% lo hicieron durante la campaña electoral ${ }^{29}$.

En nuestra investigación, los períodos de mayor concentración de publicidad institucional coinciden con los últimos meses del año inmediatamente anterior a la celebración de las elecciones autonómicas (1999, 2003 y 2007).

Una distribución similar obtenemos al analizar desagregados los datos relativos a los tres sectores más importantes (Gráfico 3), donde, además, se aprecia el paralelismo entre el «Total» y los sectores «Información de actuaciones» y «Educación/Cultura/Investigación», así como las diferencias con el de «Promoción de calidad».

Gráfico 3. Inserciones principales sectores. 1999-2009

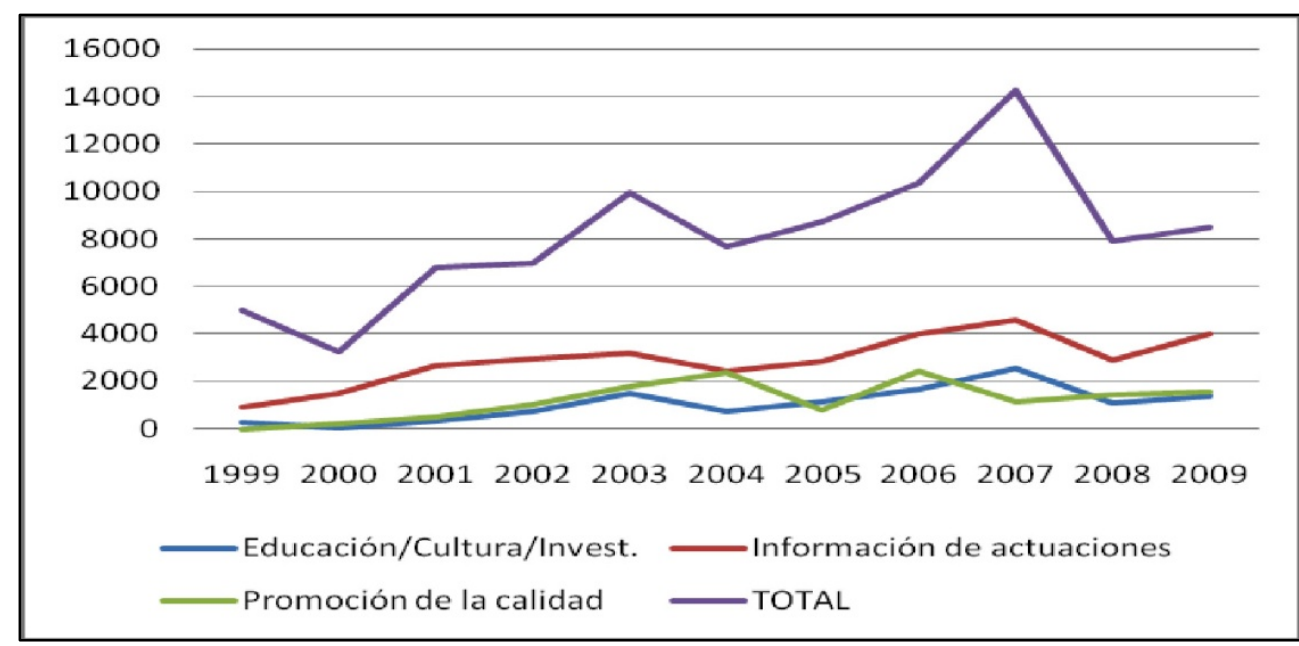

Elaboración propia a partir de Infoadex.

\subsubsection{Las campañas de interés público de la Junta de Andalucía y las elecciones}

En Andalucía, las elecciones al parlamento andaluz se convocan al tiempo que las elecciones generales españolas. En el período analizado, concurren tres años electorales: 2000, 2004 y 2008. Grosso modo, se ha constatado que el número de inserciones va aumentando a medida que avanza cada legislatura y que las máximas cotas se alcanzan precisamente en los años previos a cada uno de los procesos electorales, cayendo en los años de elecciones. No obstante, si analizamos la distribución mensual de las inserciones de los tres años electorales, observamos que la mayor parte corresponde a

29 Debemos subrayar que difícilmente se pueden inferir los datos relativos a una legislatura a partir del análisis de los de un solo año. Máxime, cuando las elecciones autonómicas no tienen lugar al mismo tiempo, como ocurre en la mayoría de los casos tenidos en cuenta por Guerrero Serón (Andalucía / Cataluña / País Vasco / Madrid y Comunidad Valenciana). 
los cinco meses previos a cada una de las jornadas electorales, que se celebraron el 12 , 14 y 9 de marzo de 2000, 2004 y 2008 , respectivamente.

El Gráfico 4 muestra claramente cómo el número de inserciones crece en los meses previos a las elecciones autonómicas (celebradas las tres en el mes de marzo): último trimestre del año anterior y primer trimestre del año electoral. En las elecciones celebradas el 12 de marzo de 2000, el 50,96\% de las inserciones de todo el año se produjeron en los tres primeros meses. Sin embargo, en las del 14 de marzo de 2004, caen al 25,13\%; algo parecido ocurre en las del 9 de marzo de 2008, con el 35,59\%.

Ahora bien, si analizamos el último trimestre de los años previos a los años de las elecciones, obtenemos unos valores altos en los años 1999 y 2007, que están bastante por encima de la media de las inserciones del último trimestre de la serie 1999-2009, que es del $39,07 \%$.

Pero además, si a estas cifras se añaden las inserciones de enero y febrero de los años electorales, es decir, si consideramos el total de inserciones en los cinco meses previos a la fecha de las elecciones (octubre-febrero), resultan unas cifras muy abultadas para los períodos de 1999-2000 y 2007-2008. En el primero, se producen el $48,97 \%$ de todas las inserciones del año 1999 y el 34,53\% del año 2000. En el segundo, el $51,45 \%$ de todo el año 2007 y el $35,59 \%$, del 2008 .

En lo concerniente a los sectores dominantes en los años electorales (tabla 4), las campañas sobre «Información de actuaciones» son, en los tres, las más numerosas. Tras ellas, destacan en el año 2000, las 591 inserciones de «Elecciones»; las 404,5 de «Deportes»y las 191, de «Promoción de la calidad».

En el año 2004, siguen siendo las inserciones más numerosas -2.398- las de «Información de actuaciones»; sin embargo, muy próximas están las relativas a «Promoción de la calidad»-2.346,5-, ocupando el tercer lugar las de «Consumo», con 725. Llama la atención, asimismo, las 712 inserciones en «Educación/ Cultura/Investigación», pues en el año electoral previo (2000) apenas llegaban a las 62 inserciones.

Este comportamiento varía algo en el año 2008: se mantiene con el mayor número de inserciones «Información de actuaciones» $(2.881,5)$; en segundo término, las de «Promoción de la calidad» (1.409,5); en tercer lugar, las de «Elecciones» (1.267).

Por otra parte, llama la atención la inexistencia de campañas «Anti-alcohol» en el año 2008, de «Anti-tabaco» en 2004 y 2008, contra la droga en 2000 y 2008, y de «Denominación de origen» en 2000 y 2004. Igualmente, es singular la caída de las inserciones en «Deportes»: de 404,5 en 2000, llegaron apenas a 5, en 2008.

Lo que resulta evidente a la vista de los resultados es que la celebración de elecciones parece condicionar, tanto cuantitativa (número de inserciones) como cualitativamente (sectores a que pertenecen), la actividad publicitaria de la Junta de Andalucía. 
Gráfico 4. Distribución por meses de inserciones anuales. 1999-2009
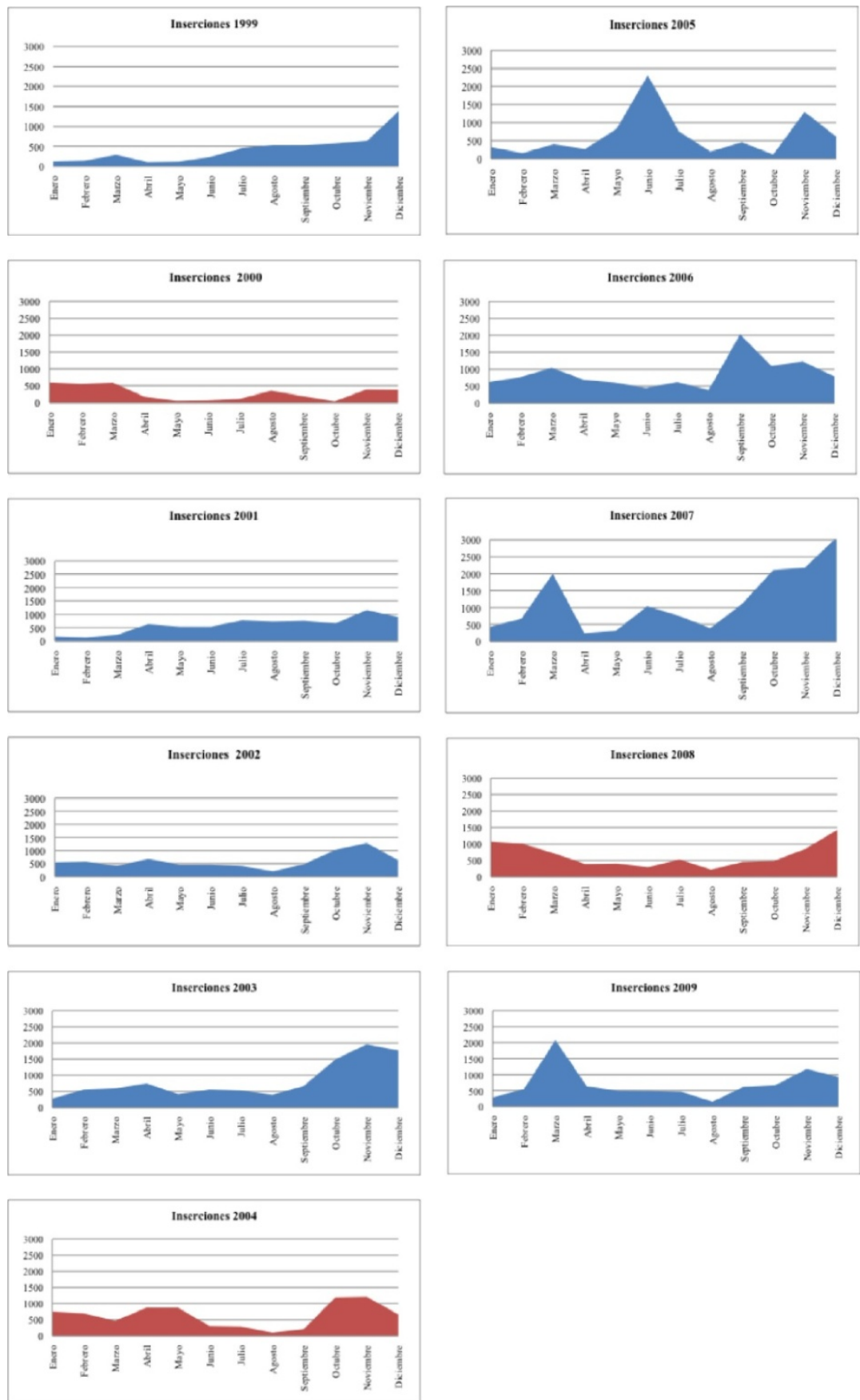

Elaboración propia a partir de Infoadex. 
Tabla 4. Inserciones por sectores en años electorales (2000, 2004 y 2008)

\begin{tabular}{|l|r|r|r|}
\hline Producto & $\mathbf{2 0 0 0}$ & $\mathbf{2 0 0 4}$ & $\mathbf{2 0 0 8}$ \\
\hline Agua y energía & 6 & 43 & 8 \\
\hline Anti-alcohol & 7 & 32,5 & 0 \\
\hline Anti-tabaco & 13 & 0 & 0 \\
\hline Antidroga & 0 & 84 & 0 \\
\hline Consumo & 70,5 & 725 & 335,5 \\
\hline Denominación de origen & 0 & 0 & 28 \\
\hline Deportes & 404,5 & 39 & 5 \\
\hline Educación/Cultura/Invest. & 62,5 & 712 & $1.064,5$ \\
\hline Elecciones & 591 & 660 & 1.267 \\
\hline Empleo & 141,5 & 27 & 94 \\
\hline Imagen de instituciones & 55 & 165 & 92,5 \\
\hline Impuestos & 0 & 6 & 0 \\
\hline Incendios & 0 & 0 & 260 \\
\hline Inf.de actuaciones & 1.491 & 2.398 & $2.881,5$ \\
\hline Limpieza y ecología & 93 & 209 & 232,5 \\
\hline Promoción de la calidad & 191 & $2.346,5$ & $1.409,5$ \\
\hline Sanidad & 108,5 & 187 & 201 \\
\hline Uso transportes públicos & 0 & 11 & 8 \\
\hline Total & $\mathbf{3 . 2 3 4 , 5}$ & $\mathbf{7 . 6 4 5}$ & $\mathbf{7 . 8 8 7}$ \\
\hline Elaboración propia a partir de Infoadex. & & & \\
\hline
\end{tabular}

\subsubsection{Medios y soportes}

La distribución en los medios de las inserciones durante el período analizado muestra un predominio de la televisión con casi un 57,86 por ciento del total, seguida de diarios, con un $24 \%$, cine con un $7,02 \%$ e Internet, con un $6,09 \%$; el resto -exterior, radio, revistas y suplementos dominicales-, se sitúan por debajo del 3\%. Llama la atención el tercer lugar del cine, dado que en términos de penetración (desde un $10 \%$ hasta un 4\%) está muy lejos de medios como los diarios (entre el $35 \%$ y el $40 \%$ en el período considerado) o la radio (entre el $55 \%$ y el $60 \%)^{30}$.

30 Los datos referidos a la penetración de los medios proceden del INE y corresponden a la situación en España. 
Tabla 5. Inserciones por medios. 1999-2009

\begin{tabular}{|c|c|c|}
\hline Medio & Inserciones & $\%$ \\
\hline Televisión & $51.700,5$ & 57,86 \\
\hline Diarios & $21.471,5$ & 24,00 \\
\hline Cine & $6.279,0$ & 7,02 \\
\hline Internet & $5.446,0$ & 6,09 \\
\hline Exterior & $2.247,0$ & 2,51 \\
\hline Radio & $1.120,5$ & 1,25 \\
\hline Televisión temática & 699,0 & 0,78 \\
\hline Revistas & 330,5 & 0,36 \\
\hline Suplementos y dominicales & 46,5 & 0,10 \\
\hline TOTAL & $89.340,5$ & \\
\hline
\end{tabular}

Elaboración propia a partir de Infoadex.

Sobre los datos de Internet, hay que precisar que se ofrecen a partir de 2001, de manera que la concentración temporal es mayor. No obstante, una presencia importante de inserciones en Internet no se produce hasta el año 2005, con 1.494, ya que en los dos años precedentes sólo se constatan 2 inserciones; por otra parte, la cifra del 2005 se rebajó drásticamente en los tres años siguientes (185, en 2006; 195, en 2007 y 578, en 2008), no volviendo a superarse hasta 2009 con 2.625 inserciones.

Gráfico 5. Inserciones televisión y otros medios. 1999-2009

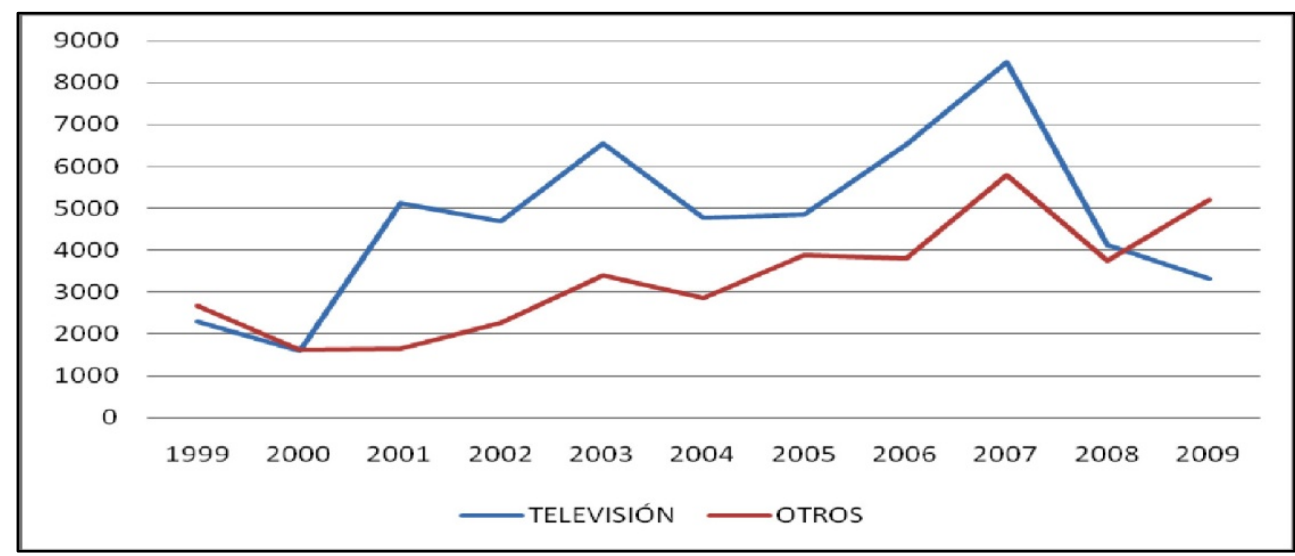

Elaboración propia a partir de Infoadex.

Grosso modo, puede afirmarse que la evolución del medio TV y la de «Otros medios» discurren prácticamente paralelas; en ambas, se aprecia un aumento en los años 2003 y 2007, en concreto en el último trimestre, es decir, los años previos a los de las elecciones. Esta tendencia al alza es muy llamativa a finales de 2007, cuando se alcan- 
zan las 14.270,5 inserciones, prácticamente el doble que en 2008 (7.887) y un tercio más que en el $2006(10.342,5)$. Además, al crecimiento intensivo que reflejan las gráficas, hay que añadir el crecimiento extensivo a partir del año 2007, cuando se observan inserciones en todos los medios.

Gráfico 6. Total publicidad institucional y total inserciones en televisión. 1999-2009

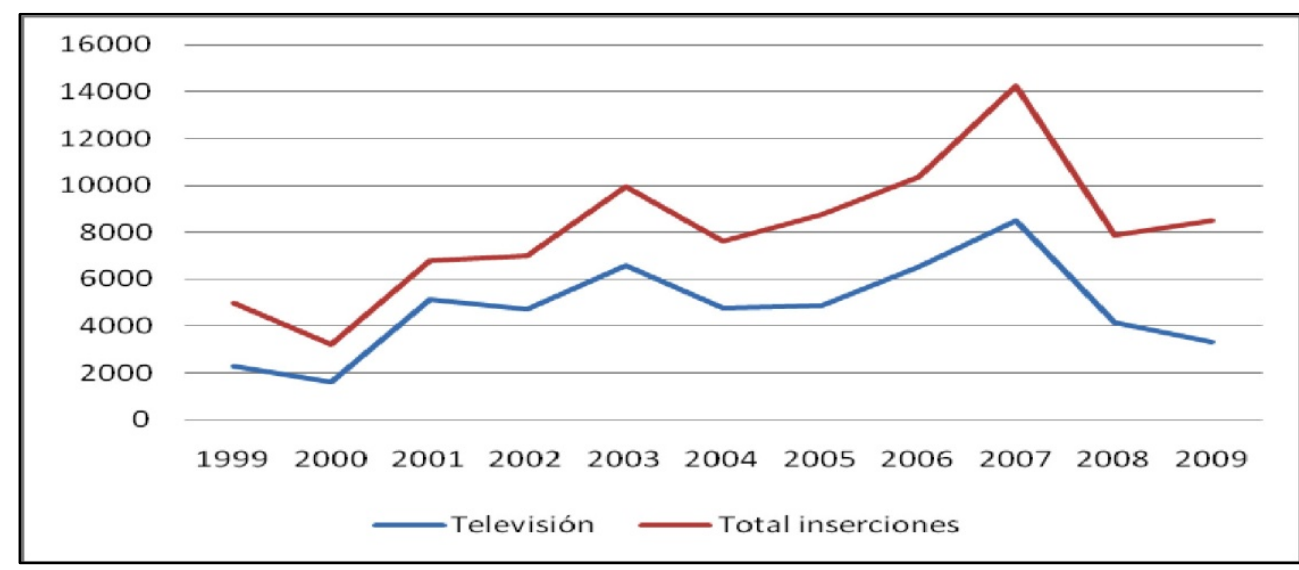

Elaboración propia a partir de Infoadex.

Por otra parte, el despegue de la televisión se produjo a partir de 2006, tres años después del aumento de las inserciones de la publicidad institucional de la Junta de Andalucía. (Gráfico 2).

En lo que respecta a los soportes utilizados en los diferentes medios, se han analizado la televisión y los diarios, ya que son los que presentan las cifras más elevadas.

Tabla 6. Inserciones principales canales de televisión. 1999-2009

\begin{tabular}{lrrr}
\hline Televisión & $\mathbf{1 9 9 9 - 0 9}$ & $\mathbf{\%}$ & $\mathbf{\%}$ \\
\hline Canal Sur TV & $24.954,0$ & 48,26 & $\mathbf{7 0 , 6 4}$ \\
Canal Sur 2 & $11.575,0$ & 22,38 & \\
C.R. 1 And. & $6.664,0$ & 12,88 \\
Ant. 3 And. & $2.953,5$ & 5,71 \\
C.R. 2 And. & 2.373 & 4,58 \\
Total 5 primeros canales & 48.519 & 93,81 \\
\hline Total todos los canales & $51.700,5$ & & \\
Elaboración propia a partir de Infoadex. & &
\end{tabular}


La gran mayoría de las inserciones publicitarias televisivas de la Junta $(93,81 \%)$ se realizó sólo en cinco canales: el 70,64\%, en las televisiones públicas autonómicas (el $48,26 \%$ en Canal Sur y el 22,38\%, en Canal Sur 2); el 17,46\%, en los Circuitos Regionales de TVE; y el 5,71\% en Antena 3 Andalucía. Aun no disponiendo de datos históricos de la penetración de los distintos soportes en el ámbito territorial que nos ocupa, y que permitirían un análisis en profundidad, sí parece posible afirmar que se privilegian ostensiblemente los distintos canales autonómicos, dependientes de la Junta de Andalucía.

En la prensa, también se observa un alto grado de concentración, sobre todo al agrupar las distintas ediciones de un mismo grupo de comunicación; así, todas las cabeceras del Grupo Joly (Diario de Cádiz, Diario de Sevilla, Diario de Jerez, El Día de Córdoba, Europa Sur, Granada Hoy, Huelva Información y Málaga Hoy), con 6.781,5 inserciones representan el 31,58\% del total de las inserciones en diarios.El grupo Vocento (ABC Sevilla, ABC Córdoba, Ideal de Granada, Sur Málaga y La Voz de Cádiz) alcanza las 5.215 inserciones, esto es, el 24,28\%. Otros grupos con diarios relevantes en inserciones son el Grupo Alfonso Gallardo (Correo de Andalucía y Diario Jaén), con 2.685 inserciones (12,50\%); Prisa (La voz de Almería), con un 6,29\%; el grupo Zeta (Córdoba), con un 5,10\% y el grupo Moll-Prensa Ibérica (La Opinión de Málaga), con un 3,34\%. Esto es, el 83,09\% de todas las inserciones se reparte entre seis grupos de comunicación.

Por otra parte, y considerando cada una de las cabeceras, es posible establecer tres grupos: 1) los que llegan, o superan las mil inserciones; 2) los que se sitúan entre 500 y 999 inserciones, y 3) los que están por debajo de las 500 inserciones.

En el primero, estarían ABC Sevilla, Córdoba, Correo de Andalucía, Diario de Cádiz, Diario de Sevilla, Huelva Información, Ideal de Granada, Jaén, La Voz de Almería y Sur Málaga. Entre todos alcanzan las 12.613,5 inserciones, lo que significa el 58,74\% del total.

El segundo grupo -ABC Córdoba, Diario de Jerez, El Día de Córdoba, Europa Sur, Granada Hoy, La Opinión de Málaga y Málaga Hoy- llega a las 4.929 inserciones, esto es, $22,95 \%$.

El tercer grupo, con 4.285 inserciones, e integrado por algunos diarios de referencia como los gratuitos 20 minutos, ADN, Metro y el deportivo Marca en su edición autonómica, supone apenas un $18,70 \%$ del total.

Según lo observado, la gran mayoría de inserciones se produjo en soportes de la Comunidad de Andalucía: el 93,81\% en televisión, y el 97,45\% en diarios; de manera que el ámbito de difusión de la publicidad institucional de la Junta de Andalucía se circunscribe «al ámbito de competencias del organismo emisor» ${ }^{31}$; o, lo que es lo mismo, la publicidad institucional se dirige esencialmente al público interno de la propia comunidad, lo que no deja de ser significativo si tenemos en cuenta la relativa importancia de las inserciones correspondientes al sector «Promoción de la calidad».

31 GuERrero SERÓn, C.A. (2009), op. cit., 82, apunta que «sólo en el caso de algunas autonomías se ha roto este criterio como consecuencia de campañas puntuales». 
Tabla 7. Inserciones principales diarios. 1999-2009

\begin{tabular}{|l|r|lr|}
\hline 500-1.000 inserciones & & $>1000$ inserciones \\
\hline ABC Córdoba & 864 & ABC Sevilla & 1.573 \\
\hline Diario de Jerez & 796,5 & Jaén & 1.515 \\
\hline Europa Sur & 785,5 & La Voz de Almería & $1.351,5$ \\
\hline La Opinión de Málaga & 719 & Ideal de Granada & 1.250 \\
\hline El Día de Córdoba & 657 & Sur Málaga & 1.223 \\
\hline Málaga Hoy & 640 & Diario de Cádiz & $1.190,5$ \\
\hline Granada Hoy & 467 & Correo de Andalucía & 1.170 \\
& & Diario de Sevilla & $1.157,5$ \\
& & Córdoba & $1.095,5$ \\
& & Huelva Información & $1.087,5$
\end{tabular}

Elaboración propia a partir de Infoadex.

Por último, la evolución de todos los medios a lo largo del período analizado, descubre el incremento de los principales -televisión, diarios- en los años previos a los procesos electorales, lo que viene a coincidir con el fuerte incremento, ya comentado, de las inserciones de campañas de interés público en el último trimestre de dichos años.

Gráfico 7. Inserciones todos los medios. 1999-2009

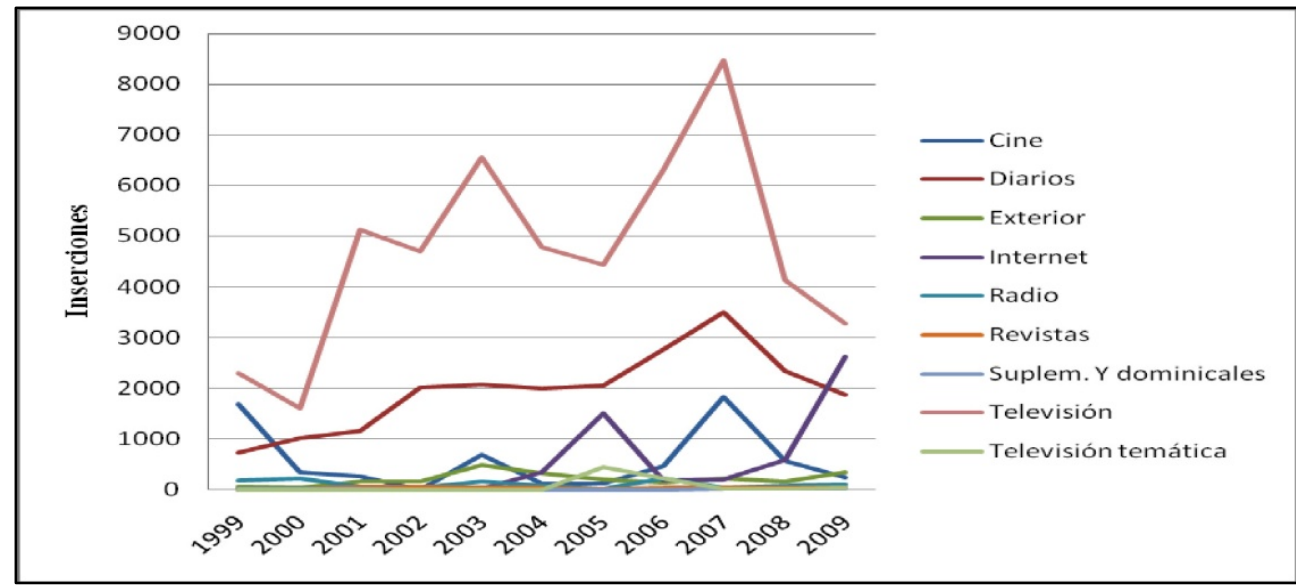

Elaboración propia a partir de Infoadex. 


\section{Conclusiones}

En la Comunidad de Andalucía, la publicidad institucional empezó a regularse en noviembre de 1995 por una ley autonómica, que fue derogada en 1999 por otra ley autonómica que, a su vez, lo fue por la vigente ley de 2005 en la que se establecen, entre otros aspectos, los objetivos de la misma.

La Junta de Andalucía es, en términos absolutos, el cuarto anunciante entre los gobiernos autónomos, tras la Comunidad de Madrid, la Generalitat de Cataluña y la Generalitat Valenciana; cerca de ella, pero por detrás, se sitúan la Xunta de Galicia y el Gobierno Vasco.

Su actividad publicitaria (el $61,03 \%$ de toda la publicidad institucional andaluza) se centra fundamentalmente en campañas de interés público (el 78,61\%), dándose además una alta concentración sectorial, prestando especial atención a tres sectores «Información de Actuaciones», «Promoción de la calidad» y «Educación/Cultura/Investigación» ${ }^{32}-$, que suponen el $63,15 \%$ del total.

Desde 1999, se produce un incremento de inserciones hasta el año 2007, cuando decrecen hasta niveles del 2003-2005, lo que puede justificarse por la incidencia de la contracción económica que sufre el país ${ }^{33}$.

En 2007 se produjo el mayor crecimiento intensivo (número de inserciones), siendo el año 2002 el que abarca mayor número de sectores.

Los años electorales presentan una distribución mensual de las inserciones distinta a la de los demás años, concentrándose la publicidad institucional en los cinco meses previos a los tres procesos electorales -2000, 2004 y 2008-. Sólo en el año 2000, se registró en el mismo mes de las elecciones (marzo) un número importante de inserciones publicitarias, lo que está prohibido (salvo las excepciones contempladas) en las diversas leyes de publicidad institucional, excepto en la valenciana. También es sorprendente el fuerte incremento de inserciones en el último trimestre del año anterior al de los procesos electorales; comportamiento que no se encuentra en los demás años analizados.

En relación a los medios utilizados, destaca la televisión, siendo los diarios, el cine e Internet los que le siguen en importancia; el resto, apenas tiene relevancia. Es llamativo que el medio cine ocupe el tercer lugar por delante de Internet; sin embargo, no hay que olvidar que los datos de este último se ofrecen a partir de 2001 y que, como se ha precisado anteriormente, si se considera la serie 2001-2009, las inserciones de Internet superarían a las del cine.

32 Estos resultados no se compadecen con la afirmación de que "mientras las administraciones locales y estatales priman las campañas sobre obras y servicios, las administraciones autonómicas publicitan, sobre todo, cuestiones de política social”, sostenida en GUERRERO SERÓN, C.A. (2009): «La publicidad institucional..., 126 y en REY, J. (2009): «A propósito de la publicidad institucional», Questiones Publicitarias, 3.

33 En otras comunidades se produce un descenso casi igual (Cataluña) o más o menos similar (Comunidad Valenciana y Galicia); sin embargo, y a pesar de dicha contracción económica, el número de inserciones de la Comunidad de Madrid alcanza su cifra más alta en 2009. 
Atendiendo a la evolución en todo el período, casi todos los medios incrementan el número de inserciones el año previo al de las elecciones, sobre todo, los cinco meses antes de los comicios. Categórico es el caso del cine que, en el año 2003 registra 680 inserciones; en el 2002, ninguna y en el 2004 (elecciones), 115. Parecido comportamiento tiene en el período electoral siguiente, con 1.822 inserciones en el 2007 y 572 en el 2008 (elecciones).

En televisión, los soportes de mayor uso son los canales autonómicos, seguidos de Antena3 Andalucía, por delante incluso de los circuitos regionales de TVE.

Respecto a los diarios, parece que la distribución de la publicidad institucional responde, en gran medida, a lo que cabría esperar en función de la tirada de los mismos. Ahora bien, se aprecian diversas cuestiones que es preciso señalar. Primero, entre los diarios de mayor audiencia, se hallan con diferencia los gratuitos -20 Minutos, Que y ADN-y los deportivos Marca, As y Sport, dándose la circunstancia de que el número de inserciones en ellos es reducidísimo. Quizá la explicación habría que buscarla en que ninguna de estas dos tipologías periodísticas contiene temas políticos, ideológicos y de opinión, de forma que parece lógico creer que carecen de interés para contener publicidad institucional. Segundo, los diecisiete primeros diarios en número de inserciones $(81,69 \%$ del total) pertenecen a empresas y grupos mediáticos muy relevantes en el espectro de los medios de comunicación en España: Joly, Vocento, Alfonso Gallardo, Zeta, Prisa, Moll-Prensa Ibérica. En los dos primeros aparece el 55,86\% de la publicidad institucional de la Junta de Andalucía.

El estudio de los sectores pone de manifiesto que un gran porcentaje de la publicidad institucional de la Junta de Andalucía tiene carácter corporativo: un $41,82 \%$ del total en toda la serie de años. Muchas de estas campañas se corresponderían con las que tienen como finalidad destacar los logros de gestión o los objetivos alcanzados (las llamadas campañas de autobombo); no en vano, la propia ley de publicidad institucional andaluza lo recoge en el apartado i del artículo 3. Otras comunidades autónomas, en cambio, lo prohíben expresamente.

Junto a las inserciones pertenecientes al ámbito corporativo destacan las del comercial $(22,19 \%)$, ocupando los últimos puestos las de carácter social.

Parece, a tenor del análisis, que el fin primero y último de la publicidad institucional -el bien público- ocupa un lugar secundario, siendo prioritario favorecer intereses y logros del gobierno autonómico.

\section{Referencias bibliográficas}

AEAP (1991): La publicidad en la administración española, Madrid, AEAP.

ALAMEDA GARCÍA, D.; FerNÁNDEZ BLANCO, E. (2002): «Aproximación conceptual a la publicidad institucional», Sphera Publica: Revista de Ciencias Sociales y de la Comunicación, 2, UCAM, 159-174. 
AlCARAZ, M. (1992): «Reflexiones sobre la publicidad institucional», en VV.VV.: El espacio televisivo a partir de la Directiva 89/552 de las Comunidades Europeas, Valencia, Ente RTVV.

AlvarADO, C.; DE ANDRÉS, S. (2005): «Una reflexión crítica sobre la publicidad estatal. El Estado ¿anunciante social?», Telos: Cuadernos de comunicación, tecnología y sociedad, 64, Fundación Telefónica, 67-73.

ÁlvareZ, A.; REYES, Mª. (2011): «De la publicidad espectáculo a los valores emocionales: el sector de la energía en España», Área Abierta, 28.

Dirección: http://revistas.ucm.es/inf/15788393/articulos/ARAB1111130001A.pdf. Web visitada el 15/03/2011.

ARANES, J. I. (1996): «La comunicación institucional de la administración pública: entre la lógica autista-instrumental y la democrática», Zer, 1, 201-213.

CORTÉS GONZÁlEZ, A. (2008): «Conceptualización de la publicidad institucional en su dimensión socializadora y educativa», Espacios Públicos, 11, [Toluca, Universidad Autónoma del Estado de México]. Dirección http://redalyc.uaemex.mx /pdf/676/67602212.pdf. Web visitada el 15 de diciembre de 2010.

CORTÉS GONZÁLEZ, A. (2011): «La publicidad institucional en España. Una década en perspectiva», Razón y Palabra, 75.

Dirección http://www.razonypalabra.org.mx/ N/N75/varia_75.../17_Cortes_V75.pdf. Web visitada el 7/10/2011.

Feliu AlbaladeJo, A. (2008): «Los ámbitos de la publicidad institucional», en Feliu García (ed.) Comunicación. Memoria, Historia y Modelos, Madrid, Edipo, 428-436.

FELIU AlBALADEJO, A. (2011): «La publicidad institucional en la arena parlamentaria española», Revista Latina de comunicación social, 66, La Laguna, Universidad de La Laguna, 454-481.

Feliu Albaladejo, A. y Feliu García, E. (2010): «Publicidad institucional en la Comunidad Valenciana. La Generalitat Valenciana como anunciante», XII Foro de Investigación en Comunicación. La Comunicación institucional. Estado actual [Madrid, 25 de noviembre de 2010], (en prensa).

Feliu García, E.; Feliu Albaladejo, A. (2011): «La publicitat institucional a Catalunya», Comunicació: Revista de Recerca i d'Anàlisi, vol. 28 (2), Barcelona, Societat Catalana de Comunicació, 47-67.

Feliu García, E.; Quintas Froufe, N. (2010): «La Xunta de Galicia como anunciante», XII Foro de Investigación en Comunicación. La Comunicación institucional. Estado actual [Madrid, 25 de noviembre de 2010], (en prensa).

GARCÍA LÓPEZ, M. (2001): Publicidad institucional: el Estado anunciante, Málaga, Universidad de Málaga.

GUERRERO SERÓN, C.A. (2009): «La publicidad institucional durante el primer gobierno Zapatero (2005-2006): elementos formales y estrategias de comunicación», Questiones Publicitarias, Monográfico 3, 33-136.

Ley orgánica 5/1985, de 19 de junio, del Régimen Electoral General, BOE $\mathrm{n}^{\circ}$ 147, de 20 de junio, 19110-19134.

Ley 5/1995, de 6 de noviembre, Reguladora de la Publicidad Institucional, Boletín oficial de la Junta de Andalucía n ${ }^{\circ} 142$ de 11 de noviembre, 10566-10567.

Ley 4/1999, de 11 de mayo, Reguladora de la Actividad Publicitaria de las Administraciones Públicas de Andalucía, $B O E$ n $^{\circ} 137$ de 9 de junio, 22118-22120. 
Ley 6/2005, de 8 de abril, Reguladora de la Actividad Publicitaria de las Administraciones Públicas de Andalucía, $B O E \mathrm{n}^{\circ} 117$, de 17 de mayo,16504- 16506.

Ley 7/2003, de 20 de marzo, de Publicidad Institucional de la Comunidad Valenciana, $B O E$ n $^{\circ}$ 87, de 11 de abril de 2003, $14306-14308$.

MalalanA, A. (2004): «Fuentes de información para el análisis de la publicidad. Las bases de datos publicitarias e internet», Cuadernos de Documentación Multimedia, 15, Madrid, Universidad Complutense. Dirección http://multidoc. rediris.es/ cdm/search.php. Web visitada el 18/09/2010.

MoRAGAS I SpÀ, M. de (2005): «Publicidad institucional: comunicación y civismo», Barcelona Metròpolis Mediterránia, 6, Barcelona, Ayuntamiento de Barcelona, 72-77.

ORIOL, P. (2001): «Comunicación pública en el ámbito local», en VV.AA.: Dirección de comunicación empresarial e institucional, Barcelona, Gestión 2000, 249-274.

PINEDA, A.; REY, J. (2009): «Propaganda y publicidad institucional», Questiones Publicitarias, $3,9-32$.

Proposición de Ley reguladora de la publicidad del sector público presentada por el Grupo Parlamentario Popular en el Congreso, BOCG, n 124-1, de 19 de febrero de 192, 1-2.

REY, J. (2009): «A propósito de la publicidad institucional», Questiones Publicitarias, 3, 1-8.

RodríGUez CENTENO, J.C.; GARRIDO, M.; RAMOS, M. (2008): "Análisis comparativo de la publicidad institucional de las comunidades autónomas: objetivos y cualidades discursivas», I+C Investigar la Comunicación [recurso electrónico]: Actas y memoria final Congreso Internacional Fundacional AE-IC. Dirección

http://www.ae-ic.org/santiago2008/contents/pdf/comunicaciones/178.pdf. Web visitada el $15 / 03 / 2010$.

Recibido: 18 de mayo de 2011

Aceptado: 8 de febrero de 2012 